\title{
Corneal Melting Two Weeks after Pterygium Excision with Topical Mitomycin C: Successfully Treated with Lamellar Keratoplasty and Amnion Membrane Transplantation
}

\author{
Moreno Menghini $^{a} \quad$ Stephanie L. Watson $^{b} \quad$ Martina M. Bosch ${ }^{a}$ \\ ${ }^{a}$ Department of Ophthalmology, University Hospital of Zurich, Zurich, Switzerland; \\ ${ }^{\mathrm{b}}$ Save Sight Institute, The University of Sydney, Sydney, N.S.W., Australia
}

\section{Key Words}

Mitomycin C P Pterygium · Corneal melting · Amniotic membrane $\cdot$ Lamellar keratoplasty

\begin{abstract}
Purpose: To report the management of a case of corneal melting two weeks after pterygium excision with intraoperative topical mitomycin C (MMC).

Methods: Case report.

Results: A 57-year-old male was referred to our Department for therapy of rapidly progressive corneal melting two weeks after primary pterygium surgery with MMC (0.2 $\mathrm{mg} / \mathrm{ml}$ ) in September 2009. Initial treatment consisted of topical and systemic immunosuppression along with topical antibiotics. Eight days after presentation, the patient underwent successful lamellar keratoplasty and amnion membrane transplantation.

Subconjunctival injection of triamcinolone $(40 \mathrm{mg} / \mathrm{ml})$ and topical bevacizumab were used to manage the increased fibrovascular activity around the site of the former pterygium.

Conclusion: Topical use of MMC during pterygium surgery may be related to serious postoperative complications such as progressive inflammatory corneal melting. The etiology may be multifactorial, which is related to MMC-induced inflammation and/or induced apoptosis. A therapeutic option is the described combination of systemic and local antiinflammatory treatment along with lamellar keratoplasty and amniotic membrane transplantation. Adjunctive therapy may be needed if recurrence occurs.
\end{abstract}




\section{Introduction}

Current research demonstrates that pterygium is a proliferative disease with hyperplastic growth of the corneoconjunctival fibrovascular tissue onto the cornea [1]. Surgical therapy can be used to successfully manage pterygia; however, recurrence remains a problem [2].

To reduce recurrence, surgical management may include autoconjunctival grafting [3], lamellar keratoplasty [4], amniotic membrane transplantation [5], and mitomycin C (MMC) [6]. Autologous conjunctival grafting has been shown to be the best technique, as it has low recurrence and adverse events rates [7]. Technically easier and therefore widely applied with primary pterygium excision is MMC. MMC is an antibiotic isolated from Streptomyces caespitosis, which interferes with RNA, DNA and protein synthesis. The topical use to prevent pterygium recurrence was first described in 1963 in Japan [8]. Though significantly reducing recurrence rates, MMC can cause scleral necrosis, secondary glaucoma, iritis, cataract, corneal edema, corneal perforation, and endophthalmitis [9]. The overall incidence of scleral necrosis after pterygium surgery has been reported as $0.2-4.5 \%$ with higher rates being linked to the use of MMC [10]. Scleral thinning can occur as early as one week postoperatively or even years after the use of topical MMC and is independent of intra- or postoperative delivery [11]. The management of surgically induced scleral necrosis associated with MMC postpterygium is complex and shows variable success.

The purpose of this report is to present a case of a serious complication after intraoperative MMC administration in order to illustrate a successful management strategy: the use of surgical repair by lamellar keratoplasty and amniotic membrane along with the control of ocular surface inflammation.

\section{Case Report}

A 57-year-old male was referred to the Department of Ophthalmology at the University Hospital of Zurich, Zurich, Switzerland, for the treatment of progressive painful peripheral corneal melting in the left eye two weeks after pterygium surgery with intraoperative MMC. Primary excision had been performed at another institution, using a bare sclera technique combined with application of 0.2 $\mathrm{mg} / \mathrm{ml}$ MMC to the scleral bed for $2 \mathrm{~min}$. Primary closure of the conjunctiva had been achieved by a continuous suture with Vicryl ${ }^{\circledR}$ 8-0 (Ethicon Inc., Blue Ash, Ohio, USA). The postoperative management consisted of Tobradex ${ }^{\circledast}$ eye drops tid $(3 \mathrm{mg}$ tobramycin and $1 \mathrm{mg}$ dexamethasone/1 ml; Alcon Laboratories Inc., Fort Worth, Tex., USA). After one week, the patient was changed to Floxal $\mathrm{SDU}^{\circledR}$ eye drops (Ofloxacin; Bausch and Lomb, Rochester, N.Y., USA) and $5 \mathrm{~g}$ vitamin $\mathrm{A}^{\circledR}$ ointment tid (vitamin A; Bausch and Lomb).

At first presentation, his best corrected visual acuity (OD $+1.75 \mathrm{sph} / \varnothing$ cyl; OS $+1.25 / \varnothing$ cyl) was $20 / 20$ in the right eye and 20/60 in the left eye. The patient reported he had strictly adhered to the prescribed postoperative regimen and denied any other medical conditions, including any rheumatic disease. On slit-lamp examination, the left eye showed a nasal crescent-shaped area of corneal ulceration measuring $2.5 \times 2.0 \mathrm{~mm}$ reaching Descemet's membrane with adjacent severe conjunctival and scleral injection ( $\underline{\text { fig. } 1}$ ). Anterior chamber assessment showed concomitant mild cellular and fibrin reaction. His corneal smears, looking for evidence of a bacterial, viral and/or fungal infection, were negative. Complete blood count, electrolytes and inflammatory markers were also within normal ranges. In particular, immunological testing did not reveal any pathological elevation of ANA or ANCA. 
The patient was admitted for pulse corticosteroid therapy with $0.1 \%$ Dexafree ${ }^{\circledR}$ UD eye drops every $2 \mathrm{~h}$ (dexamethasone; Théa Pharma, Clermont-Ferrand, France) and 250 mg Solu-Medrol ${ }^{\circledR}$ tid intravenously (methylprednisolone; Pfizer AG, New York, N.Y., USA). Floxal SDU eye drops were given every $2 \mathrm{~h}$ as a prophylaxis against infection. To inhibit collagenolysis, the patient was treated with 100 mg Vibramycin ${ }^{\circledast}$ bid orally (doxycycline; Pfizer, New York, N.Y., USA) and 10\% acetylcysteine eye drops qid. In addition, 500 mg Valtrex ${ }^{\circledR}$ tid orally (Valacyclovir; GlaxoSmithKline, London, UK) was prescribed until the diagnostic viral results were reported negative. Corneal melting stabilized under this treatment and ocular surface inflammation was reduced. Eight days after admission, when inflammation was under control, debridement of the corneal ulcer, recession of the adjacent conjunctiva, lamellar keratoplasty and amnion membrane transplantation covering the entire epithelial defect were successfully performed.

The first postoperative day showed a well-positioned lamellar corneal transplant. Local corticosteroid and antibiotic treatment was tapered and systemic corticosteroid therapy was ceased ten days postoperatively. By the third postoperative week, increased superonasal fibrovascular activity was observed at the limbus. This was interpreted as impending recurrence of the pterygium and the patient received $0.5 \mathrm{ml}$ Kenacort ${ }^{\circledR} 40 \mathrm{mg} / \mathrm{ml}$ subconjunctivally (triamcinolone; Dermapharm AG, Grünwald, Germany). Local antibiotic treatment with Floxal SDU was ceased four weeks postoperatively. $0.1 \%$ Dexafree UD eye drops were continued tid until ten weeks postoperatively and then replaced by FML Liquifilm ${ }^{\circledast}$ eye drops bid (fluorometholone; Allergan AG, Irvine, Calif., USA).

On follow-up, four and a half months after surgery, spectacle-corrected visual acuity was 20/20. The Javal-Schiötz Ophthalmometer ${ }^{\circledR}$ (Haag-Streit AG, Bern, Switzerland) showed an irregular astigmatism of $-1.5 \mathrm{dpt}$ at $100^{\circ}$, which was confirmed with the Oculus-Pentacam ${ }^{\circledR}$ (Oculus GmbH, Wetzlar, Germany). Slit-lamp examination revealed a lamellar transplant, a few stromal parapupillary opacities nasally and a deep and quiet anterior chamber. The conjunctiva bordering the nasal cornea was slightly inflamed with an area of intensive vascularization and thickening (fig. 2 ). To minimize ocular surface inflammation, all sutures were removed and a subconjunctival injection of $0.6 \mathrm{ml}$ Kenacort was given. Additionally, FML Liquifilm drops were replaced with 0.1\% Dexafree UD qid.

After a few weeks of slight regression, regrowth of the fibrovascular pannus was observed at the edge of the lamellar graft and $5 \mathrm{mg} / \mathrm{ml}$ bevacizumab eye drops (hospital pharmacy, University Hospital of Zurich, Zurich, Switzerland) were then given topically for 4 weeks. Six months postoperatively another subconjunctival Kenacort depot was placed. Superficial inflammation was then stabilized. A new formation of anterior synechiae extending through the three o'clock position at the former site of corneal melting was detected. At 14 months postoperatively a slight increase in vascularization was noted at the edge of the amnion patch. A fourth subconjunctival injection of Kenacort was given and the patient was continued on FML Liquifilm drops once daily for another 4 months. No recurrence was noted at 24 months.

\section{Discussion}

This case illustrates a severe complication after bare sclera excision of a pterygium with intraoperative application of MMC to the scleral bed. Successful management was achieved through control of the inflammatory process and the combination of a lamellar keratoplasty and amnion membrane patch to prevent the impending corneal perforation. The amnion membrane transplant (with its anti-inflammatory properties) together with locally and systemically applied corticosteroid drugs were used to control the inflammation. Adjunctive therapy with subconjunctival steroids and antivascular endothelial growth factor (VEGF) drugs was needed to treat a minor recurrence in the postoperative period.

The aims of the primary surgery were not only to fully excise the pterygium, but also to prevent its recurrence. Mitomycin is utilized as ancillary treatment due to its antiproliferative effects. These irreversible effects of MMC might be the only cause of our patient's postoperative complication. On the other hand, apoptosis and necrosis 
might also have been triggered by the inflammatory properties of the pterygium and its excision.

This severe complication threatened the tectonic integrity of the globe. Our primary goal, therefore, had been to surgically restore the integrity of the cornea, which was successfully achieved with lamellar keratoplasty. MMC-induced complications are associated with ocular surface inflammation, which can lead to a further deterioration of the clinical situation. Our goal, therefore, was not only to restore the full corneal thickness, but also to control the ocular surface inflammation with corticosteroids and tetracyclines. An additional anti-inflammatory effect was achieved by the amnion membrane transplantation. Furthermore, the timely recognition and treatment of an impending recurrence, with subconjunctival triamcinolone injection and anti-VEGF drugs, were crucial in stopping the recurrence. Several studies have recently emphasized the importance of VEGF in the development and recurrence of pterygium [12].

Despite the above-mentioned treatment, the formation of anterior synechiae extending through the three o'clock position at the former site of corneal melting could not be prevented. It remains unclear whether the synechiae were triggered by corneal microperforations most probably existing at referral or as a consequence of surgical intervention. Since the growth of the synechiae was progressive, a possible etiology is chronic inflammation, which may have been due to the irreversible damage to the tissue on the cell level caused by MMC.

Recently described surgical options to reduce the recurrence of pterygium are recommended alternatives to bare sclera surgery [9]. The conjunctival autograft described by Kenyon et al. [3] shows low recurrence rates with minimal complications and is nowadays the preferred choice of many surgeons. In addition to the conjunctival autograft, limbal stem cell transplantation has been introduced to reconstruct the excised pterygial area as anatomically and physiologically correct as possible to theoretically reduce the recurrence rate [13]. However, some studies have shown that the recurrence rates after limbal stem cell transplantations are comparable with conjunctival autograft surgery alone [14]. Another surgical option in the primary treatment of pterygium is amniotic membrane transplantation. Despite the antiscarring, anti-angiogenic, and anti-inflammatory properties of amnion membrane, recent studies have found no advantage in terms of recurrence rates compared to conventional treatments, and some authors have even reported unacceptably high recurrence rates [5]. Recently, fibrin glue has been used to avoid suture-related complications [15]. The major drawbacks regarding fibrin glue are its costs, bovine contents, and the potential risk of transmitting infections [9].

Our case demonstrates a successful management of a severe MMC-induced complication. The corneal integrity was effectively repaired with lamellar keratoplasty and the inflammation was controlled by amniotic membrane grafting as well as the application of corticosteroids and tetracyclines. Considering the potential adverse events with the use of MMC, we believe that despite the technical challenge and the longer surgical time, the conjunctival autograft technique should be used to treat primary pterygia. 


\section{Disclosure Statement}

The authors have no conflicts of interest or sources of funding to declare.

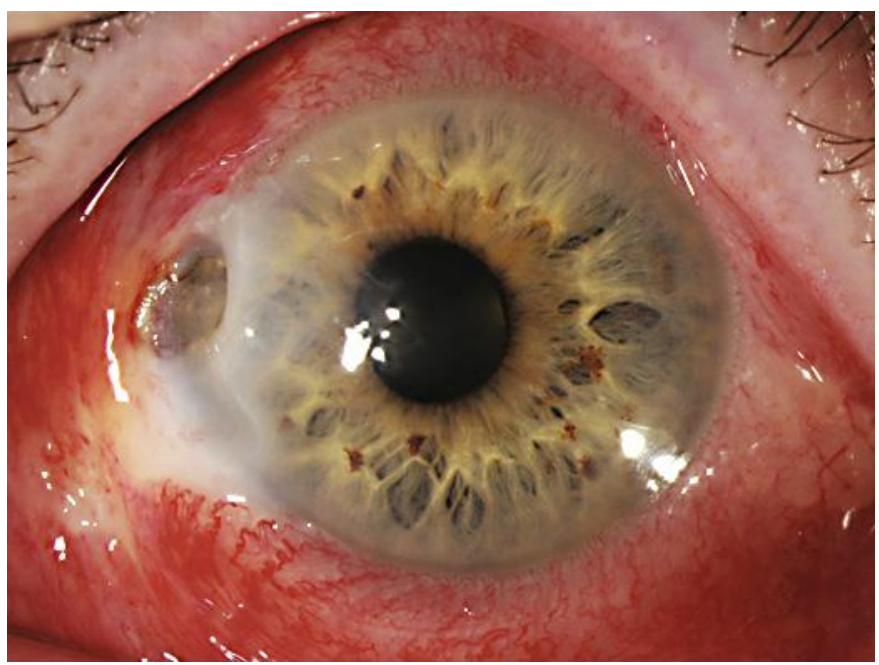

Fig. 1. The left eye at initial presentation showing a nasal crescent-shaped area of corneal ulceration $(2.5 \times 2.0 \mathrm{~mm})$, extending to Descemet's membrane. There is considerable adjacent severe conjunctival and scleral injection.

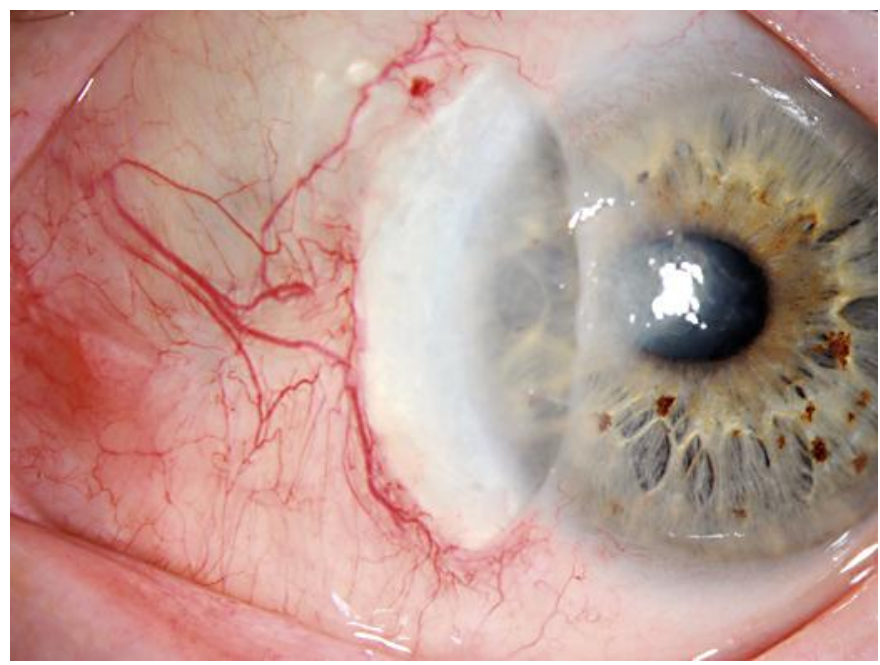

Fig. 2. At 5 months after the lamellar keratoplasty and amniotic membrane patch graft, an area of intense vascularization and thickening of the conjunctiva was noted at the edge of the graft. 


\section{References}

1 Chui J, Coroneo MT, Tat LT, et al: Ophthalmic pterygium: a stem cell disorder with premalignant features. Am J Pathol 2011;178:817-827.

-2 Mutlu FM, Sobaci G, Tatar T, Yildirim E: A comparative study of recurrent pterygium surgery: limbal conjunctival autograft transplantation versus mitomycin $C$ with conjunctival flap. Ophthalmology 1999;106:817-821.

-3 Kenyon KR, Wagoner MD, Hettinger ME: Conjunctival autograft transplantation for advanced and recurrent pterygium. Ophthalmology 1985;92:1461-1470.

-4 Das S, Ramamurthy B, Sangwan VS: Deep lamellar keratoplasty for recurrent advanced pterygium. Ophthalmic Surg Lasers Imaging 2009;40:43-45.

$>5$ Tananuvat N, Martin T: The results of amniotic membrane transplantation for primary pterygium compared with conjunctival autograft. Cornea 2004;23:458-463.

-6 Singh G, Wilson MR, Foster CS: Long-term follow-up study of mitomycin eye drops as adjunctive treatment of pterygia and its comparison with conjunctival autograft transplantation. Cornea 1990;9:331-334.

-7 Prabhasawat P, Barton K, Burkett G, Tseng SC: Comparison of conjunctival autografts, amniotic membrane grafts, and primary closure for pterygium excision. Ophthalmology 1997;104:974-985.

8 Adamis AP, Starck T, Kenyon KR: The management of pterygium. Ophthalmol Clin North Am 1990;3:611-623.

9 Ang LP, Chua JL, Tan DT: Current concepts and techniques in pterygium treatment. Curr Opin Ophthalmol 2007;18:308-313.

10 Ti SE, Tan DT: Tectonic corneal lamellar grafting for severe scleral melting after pterygium surgery. Ophthalmology 2003;110:1126-1136.

11 Wan Norliza WM, Raihan IS, Azwa JA, Ibrahim M: Scleral melting 16 years after pterygium excision with topical Mitomycin C adjuvant therapy. Cont Lens Anterior Eye 2006;29:165-167.

12 van Setten G, Aspiotis M, Blalock TD, et al: Connective tissue growth factor in pterygium: simultaneous presence with vascular endothelial growth factor - possible contributing factor to conjunctival scarring. Graefes Arch Clin Exp Ophthalmol 2003;241:135-139.

13 Tan DT, Ficker LA, Buckley RJ: Limbal transplantation. Ophthalmology 1996;103:29-36.

-14 Frau E, Labetoulle M, Lautier-Frau M, et al: Corneo-conjunctival autograft transplantation for pterygium surgery. Acta Ophthalmol Scand 2004;82:59-63.

15 Bahar I, Weinberger D, Dan G, Avisar R: Pterygium surgery: fibrin glue versus Vicryl sutures for conjunctival closure. Cornea 2006;25:1168-1172. 